\title{
Fungistatic and fungicidal properties of Candida pyralidae Y1117, Pichia kluyveri Y1125 and Pichia kluyveri Y1164 on the biocontrol of Botrytis cinerea
}

\author{
M. Mewa-Ngongang, H.W. du Plessis, S.K.O. Ntwampe, B.S. Chidi, U.F. Hutchinson, L. Mekuto and \\ N.P. Jolly
}

\begin{abstract}
The agro-processing industry is currently facing losses due to microbial spoilage of agricultural produce and associated value-added products such as beverages. To address this, synthetic chemicals that have potential human health and environmental effects have been widely used to control microbial spoilage. As a result, a bioprospecting approach that uses biological systems e.g. yeast as biocontrol agents is increasingly being considered in the food industry. The aim of the current study was to investigate the effect of varying inoculum dose (ID) of Candida pyralidae strain Y1117, Pichia kluyveri Y1125 and Pichia kluyveri Y1164 for the biocontrol of Botrytis cinerea. The headspace of the growth medium was contaminated with a fungal plug subsequent to biotreatment with different initial inoculum dose of the respective biocontrol agents. The results obtained showed that the fungistatic and fungicidal effects on the fungal pathogen was dose dependent. The fungistatic characteristics against Botrytis cinerea were displayed after 7 days when $10^{2}-10^{5}$ cells $\mathrm{mL}^{-1}$ of Candida pyralidae Y1117, Pichia kluyveri Y1125 and Pichia kluyveri Y1164 were independently used in-vitro and in-vivo. However, $10^{6}-10^{8}$ cells $\mathrm{mL}^{-1}$ inoculum doses displayed fungicidal characteristics. Additionally, the fungicidal property of yeasts studied was also confirmed on table grape (in vivo studies) using closed jars.
\end{abstract}

Keywords - Botrytis cinerea, Candida pyralidae, Fungicidal, Fungistatic, Pichia kluyveri, Volatile Organic Compounds (VOCs)

\section{INTRODUCTION}

Fruit spoilage caused by fungal pathogens is an agricultural and post-harvest challenge [1], [2]. A significant quantity of fruit is lost annually during post-harvest processing and transportation [3]-[5]. Generally, Botrytis cinerea is one of the major fungal spoilers of table grapes [6], [7]. Currently, synthetic chemicals with fungicidal properties have been used in

M. Mewa-Ngongang, H.W. du Plessis, N.P. Jolly are with the Post-Harvest and Agro-Processing Technologies, ARC Infruitec-Nietvoorbij (The Fruit, Vine and Wine Institute of the Agricultural Research Council), Private Bag X5026, Stellenbosch, 7599, South Africa.

S.K.O. Ntwampe, B.S. Chidi, U.F. Hutchinson, and L. Mekuto are with the Bioresource Engineering Research Group (BioERG), Department of Biotechnology, Faculty of Applied Sciences, Cape Peninsula University of Technology, Keizersgracht and Tennant Street, Zonnebloem, P.O. Box 652, Cape Town, 8000, South Africa.. order to reduce microbial spoilage of grapes and other fruits. It has also been widely reported that the currently used synthetic chemicals pose serious health concerns that necessitates an alternative to synthetic preservatives for fruit producers and processors [8]. The use of yeasts as biological control agents is a better alternative to the use of synthetic chemicals because of the ability to compete for nutrients, space, and to grow at a faster rate than fungal pathogens [9]-[12]. The inhibitory effect of yeasts has also been attributed to the production of volatile organic compounds (VOCs) [13], [14]. Although yeasts are known to inhibit fungal growth by releasing volatile organic compounds, their fungistatic and the fungicidal effects at varying inoculum doses has never been reported for the biocontrol of Botrytis cinerea. The aim of the study was therefore to assess the fungistatic and fungicidal activity of the yeasts Candida pyralidae strain Y1117, Pichia kluyveri strain Y1125 and Pichia kluyveri strain Y1164 against Botrytis cinerea in-vitro and in-vivo, and to determine the minimum inoculum dose (MID) of yeast required to completely inhibit Botrytis cinerea in a quantified contaminated headspace, while confirming these properties on table grapes.

\section{MATERIALS AND METHODS}

\section{A. Yeasts and Fungi Selection}

Previously, Candida pyralidae strain Y1117, Pichia kluyveri strain Y1125 and Pichia kluyveri strain Y1164 were collected from the ARC Infruitec-Nietvoorbij (Post-Harvest Control Laboratory) and screened against various fruit fungal pathogens, including Botrytis cinerea [15]. They were then selected for the purpose of this study.

\section{B. Microorganisms Culture Condition and Inoculum Preparation}

Chenin Blanc grape pomace was collected from the ARC Infruitec-Nietvoorbij research cellar and prepared according to [15]. The yeasts were cultured in a grape pomace medium (GPM) at $150 \mathrm{rpm}$ in a shaking incubator (LM-530R Orbital) for $24 \mathrm{hrs}$ at $22{ }^{\circ} \mathrm{C}$ [16]. The resulting fermentation broth was centrifuged for $5 \mathrm{~min}$ at $5000 \mathrm{rpm}$, and the cell pellets were 
collected and resuspended in sterile distilled water. The re-suspended cells were serially diluted from $10^{1}-10^{7}$ cells $\mathrm{mL}^{-1}$. For the grape bioassay, the cell suspensions to be sprayed were diluted in GP broth adjusted to a sugar level of 150 g. $\mathrm{L}^{-1}$. The fungal plugs were prepared by excising a $5 \mathrm{~mm}$ disk from a 7 day old plate [17].

\section{Volumetric Headspace Quantification}

The volume of the headspace in the agar plates was calculated by considering the diameter and the height of the closed $90 \mathrm{~mm}$ diameter petri dish, using the approach described by [16]. The thickness $(15 \mathrm{~mm})$ of the empty petri dish was determined and the headspace volume was obtained by accounting for the volume of grape pomace agar (GPA) poured on the plate. The volume of the poured medium was also determined and subtracted from the total. The evaluation of the actual headspace in contact with the fungal pathogen was done to determine the fungistatic and fungicidal effect of the biological control agents when a specific inoculum dose was used in a quantified headspace.

\section{In-vitro Test: Mouth to Mouth Assay}

As described by [17], the mouth to mouth method was used. In brief, two GPA plates facing each other were used in each biotreatment. The bottom plate contained the biological control yeast and the top plate contained the centred $5 \mathrm{~mm}$ fungal plug. The biological control plates were prepared by spreading 100 $\mu \mathrm{L}$ of each dilutions $\left(10^{1}, 10^{2}, 10^{3}, 10^{4}, 10^{5}, 10^{6}\right.$ and $10^{7}$ cells $\mathrm{mL}^{-1}$ ) for different yeasts. The fungal plates were prepared in three replicates by placing the $5 \mathrm{~mm}$ plug at the centre of each GPA plate. All the yeast-inoculated plates were aligned (mouth to mouth) with the fungal-contaminated plates, and then sealed with laboratory film. For the negative controls, also in three replicates, the fungal plates were aligned with uninoculated GPA plates. All plates were incubated at $15^{\circ} \mathrm{C}$ for 7 days. The fungicidal characteristics were evaluated by opening the plates for an additional 7 days under similar conditions to allow VOCs to escape from the plates.

\section{E. In-vivo test: Jar method using table grapes}

For each control and treatment, 9 jars, containing $300 \mathrm{~g}$ of Regal Seedless table grapes each, were wounded [14] and allowed to dry for 15 minutes. The biological control yeasts sprayed on the berries were also allowed to dry for about an hour. The treated berries previously placed on storage trays were then infected by spraying the fungal pathogen at a concentration of $10^{5}$ spores $\mathrm{mL}^{-1}$ into the jars. The grapes were then placed in $500 \mathrm{~mL}$ volume jars and sealed with laboratory film. The negative control were free of the yeasts as biological agents. The jars were incubated at $15{ }^{\circ} \mathrm{C}$ for 7 days. Subsequently, after 7 days, the jars were opened and further incubated at $15{ }^{\circ} \mathrm{C}$ until the negative control was completely rotten. The treated jars were then compared with the negative control in order to evaluate and possibly confirm the fungicidal behaviour of the VOCs from the biocontrol yeasts. These results were assessed by monitoring the presence or absence of fungal growth after the jars had been exposed to open air.

\section{RESULTS AND DISCUSSION}

\section{A. Headspace Quantification}

Biocontrol studies have been done previously but none focused on the impact of headspace on microbial inhibition. In this study, the headspace volume in which the growth inhibition occurred was quantified. The volume covered by the GPA poured onto the petri dish was found to be $12.7 \mathrm{~mL}$. The actual headspace in which the efficacy of the VOCs produced by the biological control took place was $111 \mathrm{~mL}$ compared to $400 \mathrm{~mL}$ in vivo (total volume of headspace in the jar used).

\section{B. Efficacy of the VOCs In-vitro}

The evaluation of the effect of VOCs in a closed and quantifiable headspace was carried out. Candida pyralidae strain Y1117, Pichia kluyveri Y1125 and Pichia kluyveri Y1164 inhibited the growth of Botrytis cinerea at different inoculum dose. The $10^{1}$ cell $\mathrm{mL}^{-1}$ treatments were mostly similar to the negative control (Fig $1 \mathrm{~A}_{\mathrm{a}}, \mathrm{B}_{\mathrm{a}}$ and $\mathrm{C}_{\mathrm{a}}$ ) whereas the inoculum dose of $10^{2}-10^{5}$ cells $\mathrm{mL}^{-1}$ showed the fungistatic characteristics (Fig. 1 A, B, $\mathrm{C}_{\mathrm{b}, \mathrm{c}, \mathrm{d}, \mathrm{e}}$ ). The confirmation was also made when fungal growth was observed after opening the plates. Fungal growth inhibition was also displayed in $10^{6}-10^{8}$ cells $\mathrm{mL}^{-1}$ plates (Fig $1 \mathrm{~A}, \mathrm{~B}, \mathrm{C}_{\mathrm{f}, \mathrm{g}, \mathrm{h}}$ ). However, no fungal growth was observed after opening the plates. This was a clear indication that higher inoculum doses completely inhibit fungal growth whereas lower inoculum doses temporarily suppresses growth until VOCs escape from the container.

\section{Efficacy of the VOCs In-vivo}

To confirm the fungicidal effect observed in-vitro, the in-vivo test was carried-out using a grape bioassay. The fungicidal effect of Candida pyralidae strain Y1117, Pichia kluyveri Y1125 and Pichia kluyveri Y1164 was observed as a resultant of VOCs released (Fig. 2). Compared to the negative controls, fungal growth was still completely inhibited after leaving the jars for five weeks for all tested yeast (Fig 2). The growth inhibition of Botrytis cinerea by VOCs from yeasts have been reported in literature [14], [18]-[20] and comparing those findings to the results obtained in this work, it can be noted that the method used in this work and the VOCs produced by Candida pyralidae Y1117, Pichia kluyveri Y1125 and Pichia kluyveri Y1164 completely inhibited the growth of Botrytis cinerea on table grapes. Furthermore, the findings from this work clearly demonstrated the fungicidal potential of Candida pyralidae Y1117, Pichia kluyveri Y1125 and Pichia kluyveri Y1164 for the biocontrol of Botrytis cinerea. The minimum inoculum dose (MID) strategy proved beneficial in exploring the interactive relationship between yeasts and fruit fungal pathogens. 
For all yeasts, the MID of $10^{6}$ cells $\mathrm{mL}^{-1}$ was sufficient to display fungicidal activity against Botrytis cinerea. Since a more preventative approach against Botrytis cinerea was adopted in this study, the inoculum dose and headspace findings could be used to model and optimise biofungicide activities of yeasts under commercial transportation and storage condition.

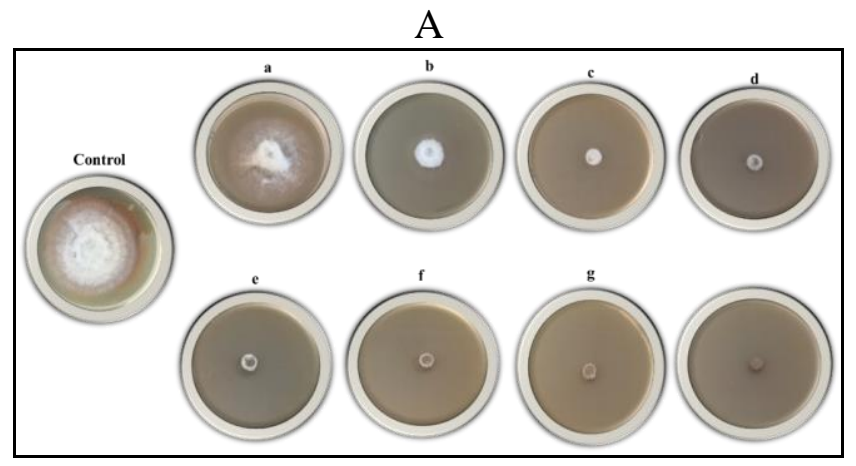

B

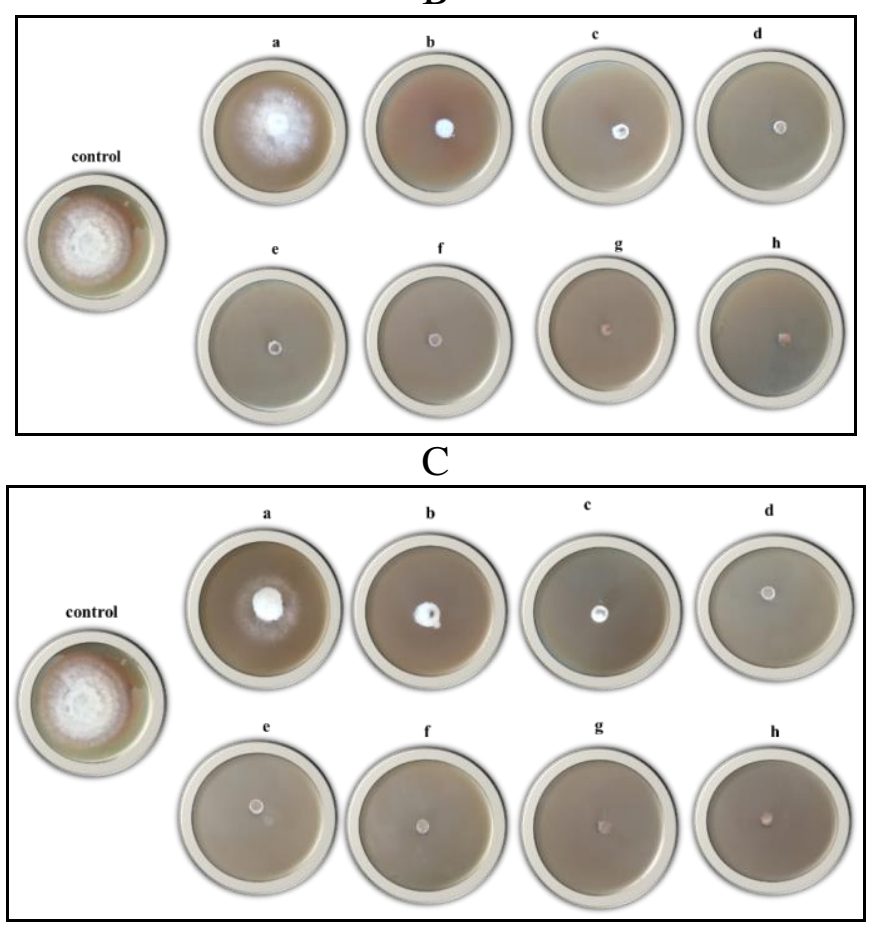

Fig. 1: Representative agar plates showing the in-vitro fungistatic and fungicidal effect of Candida pyralidae Y1117 (A), Pichia kluyveri Y1125 (B) and P. kluyveri Y1164 (C) on the biocontrol of Botrytis cinerea. (a) represents the plates spread with initial inoculum of $10^{1}$ cells $\mathrm{mL}^{-1}$; b, c d and e depict the initial inoculum of $10^{2}, 10^{3}, 10^{4}$ and $10^{5}$ cells $\mathrm{mL}^{-1}$ respectively. $\mathrm{f}, \mathrm{g}$, h correspond to the initial inoculum of $10^{6}, 10^{7}$ and $10^{8}$ cells $\mathrm{mL}^{-1}$. Assays were conducted in triplicates.
Control

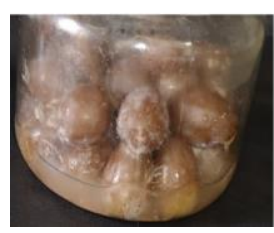

A

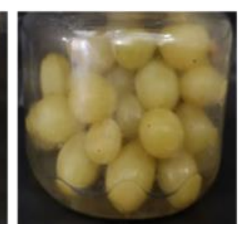

B

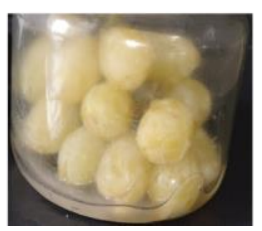

C

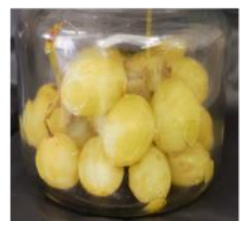

Fig. 2: Representative jars showing the fungicidal effects of Candida pyralidae Y1117 (A), Pichia kluyveri Y1125 (B) and P. kluyveri Y1164 (C) on the biocontrol of Botrytis cinerea. Only one jar per treatment was selected as a representative.

\section{CONCLUSION}

This study demonstrated the fungistatic and fungicidal potential of the biocontrol yeasts. The VOCs produced by $C$. pyralidae Y1117, P. kluyveri Y1125 and P. kluyveri Y1164 when trapped in a closed environment were found to be responsible for the fungicidal effect on the growth of $B$. cinerea both in-vitro and in-vivo. The use of yeast with biocontrol activity presents a potential alternative to synthetic chemicals currently used as fungicides on fruit and other fruit derived beverages.

\section{ACKNOWLEDGMENT}

The Agricultural Research Council (ARC), the National Research Foundation (NRF) of South Africa, colleagues, students and Mr Edwin Hlangwani are acknowledged for the infrastructural resources, financial support and technical assistance.

\section{REFERENCES}

[1] M.A.M. Salman, "Biological Control of Rhizopus Soft Rot on Apple, Pear and Peach by Trichoderma harzianum," PhD Thesis. An-Najah National University, December 2005.

[2] S. Parveen, A.H. Wani, M.Y. Bhat, J.A. Koka, and F.A. Wani, "Management of postharvest fungal rot of peach (Prunus persica) caused by Rhizopus stolonifer in Kashmir Valley, India," Plant Pathology and Quarantine, vol 6 no 1 pp 19-29, 2016.

https://doi.org/10.5943/ppq/6/1/4

[3] S. Droby, "Improving quality and safety of fresh fruits and vegetables after harvest by the use of biocontrol agents and natural materials," In I International Symposium on Natural Preservatives in Food Systems vol 709, pp 45-52, May 2005.

[4] S.J. Zhu, "Non-chemical approaches to decay control in postharvest fruit," Advances in Postharvest Technologies for Horticultural Crops. Research Signpost, Trivandrum, India: pp 297-313, 2006.

[5] D. Singh, and R.R. Sharma, "Postharvest diseases of fruits and vegetables and their management," In Postharvest Disinfection of Fruits and Vegetables pp. 1-52. Academic Press, January 2018.

[6] B. Williamson, B. Tudzynski, P. Tudzynski, and J.A. van Kan, "Botrytis cinerea: the cause of grey mould disease," Molecular Plant Pathology, vol 8 no 5 pp 561-580, July 2007. https://doi.org/10.1111/j.1364-3703.2007.00417.x

[7] R.R. Sharma, D. Singh, and R. Singh, "Biological control of postharvest diseases of fruits and vegetables by microbial antagonists: A review," Biological Control, vol 50 no 3 pp 205-221, September 2009. https://doi.org/10.1016/j.biocontrol.2009.05.001

[8] P.S. Cheetham, "Combining the technical push and the business pull for natural flavours," In Biotechnology of aroma compounds. Springer: pp 1-49, December 2006.

[9] F. Comitini, J.I De, L. Pepe, I. Mannazzu, and M. Ciani, "Pichia anomala and Kluyveromyces wickerhamii killer toxins as new tools against 
Dekkera/Brettanomyces spoilage yeasts," FEMS Microbiology Letters, vol 238 no pp 235-240, September 2004.

[10] N.N. Mehlomakulu, M.E. Setati, and B. Divol, "Characterization of novel killer toxins secreted by wine-related non-Saccharomyces yeasts and their action on Brettanomyces spp," International Journal of Food Microbiology, vol 188 pp 83-91, October 2014. https://doi.org/10.1016/j.ijfoodmicro.2014.07.015

[11] M. Grzegorczyk, B. Żarowska, C. Restuccia, and G. Cirvilleri, "Postharvest biocontrol ability of killer yeasts against Monilinia fructigena and Monilinia fructicola on stone fruit," Food Microbiology, vol 61 pp 93-101, February 2017. https://doi.org/10.1016/j.fm.2016.09.005

[12] C. Nadai, W.J.F.L. Junior, F. Favaron, A. Giacomini, and V. Corich, "Biocontrol activity of Starmerella bacillaris yeast against blue mold disease on apple fruit and its effect on cider fermentation," PloS One, vol 13 no 9 pp e0204350, September 2018. https://doi.org/10.1371/journal.pone.0204350

[13] R. Huang, G.Q. Li, J. Zhang, L. Yang, H.J. Che, D.H. Jiang, and H.C. Huang, "Control of postharvest Botrytis fruit rot of strawberry by volatile organic compounds of Candida intermedia," Phytopathology, vol 101 no 7 pp 859-869, July 2011. https://doi.org/10.1094/PHYTO-09-10-0255

[14] L. Parafati, A. Vitale, C. Restuccia, and G. Cirvilleri, "Biocontrol ability and action mechanism of food-isolated yeast strains against Botrytis cinerea causing post-harvest bunch rot of table grape," Food Microbiology, vol 47 pp 85-92, May 2015. https://doi.org/10.1016/j.fm.2014.11.013

[15] M. Mewa-Ngongang, H.W. du Plessis, U.F. Hutchinson, L. Mekuto, and S.K. Ntwampe, "Use of Candida pyralidae and Pichia kluyveri for biological and post-harvest control of beverage and fruit spoilage organisms (submitted)," Postharvest Biology and Technology, 2018.

[16] M. Mewa-Ngongang, H.W. du Plessis, U.F. Hutchinson, L. Mekuto, and S.K. Ntwampe, "Kinetic modelling and optimisation of antimicrobial compound production by Candida pyralidae KU736785 for control of Candida guilliermondii," Food Science and Technology International, vol 23 no 4 pp 358-370, February 2017. https://doi.org/10.1177/1082013217694288

[17] N. Medina-Córdova, R. López-Aguilar, F. Ascencio, T. Castellanos, A.I. Campa-Córdova, and C. Angulo, "Biocontrol activity of the marine yeast Debaryomyces hansenii against phytopathogenic fungi and its ability to inhibit mycotoxins production in maize grain (Zea mays L.)," Biological Control, vol 97 pp 70-79, June 2016. https://doi.org/10.1016/j.biocontrol.2016.03.006

[18] M.C. Nally, V.M. Pesce, Y.P. Maturano, L.R Assaf, M.E. Toro, L.C. de Figueroa, and F. Vazquez, "Antifungal modes of action of Saccharomyces and other biocontrol yeasts against fungi isolated from sour and grey rots," International Journal of Food Microbiology, vol 204 pp 91-100, July 2015. https://doi.org/10.1016/j.ijfoodmicro.2015.03.024

[19] X. Qin, H. Xiao, C. Xue, Z. Yu, R. Yang, Z. Cai, and L. Si, "Biocontrol of gray mold in grapes with the yeast Hanseniaspora uvarum alone and in combination with salicylic acid or sodium bicarbonate," Postharvest Biology and Technology, vol 100 pp 160-167, February 2015. https://doi.org/10.1016/j.postharvbio.2014.09.010

[20] X. Qin, H. Xiao, X. Cheng, H. Zhou, and L. Si, "Hanseniaspora uvarum prolongs shelf life of strawberry via volatile production," Food Microbiology, vol 63 pp 205-212, May 2017. https://doi.org/10.1016/j.fm.2016.11.005

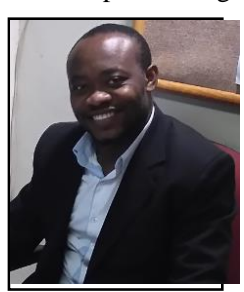

M. Mewa Ngongang was born in Bangwa (Cameroon) in 1986. He obtained his Master of Engineering in Chemical Engineering in September 2016 at the Cape Peninsula University of Technology (CPUT), Cape Town, South Africa. Prior to that he obtained a National Diploma and a Bachelor degree in Biotechnology at CPUT. Maxwell matriculated in 2007 at Bamena government high school in Cameroon. He is currently at the second year of his Doctor of Engineering study in Chemical Engineering at CPUT. Maxwell is also a NRF-ARC professional development program (PDP) candidate and is also involved in lecturing semester 4 students in Biotechnology at CPUT. 